\title{
Stress-Strain Analysis in TiN Nanocoating Deposited on Polymer with respect to Au Nanointerlayer
}

\author{
Magdalena Kopernik, Andrzej Milenin, Sławomir Kąc, and Mirosław Wróbel
}

AGH University of Science and Technology, Al. Mickiewicza 30, 30-059 Cracow, Poland

Correspondence should be addressed to Magdalena Kopernik; kopernik@agh.edu.pl

Received 8 January 2014; Revised 7 April 2014; Accepted 22 April 2014; Published 20 May 2014

Academic Editor: Krishanu Biswas

Copyright ( 2014 Magdalena Kopernik et al. This is an open access article distributed under the Creative Commons Attribution License, which permits unrestricted use, distribution, and reproduction in any medium, provided the original work is properly cited.

The multiscale analysis in the authors' finite element code confirmed possibility of fracture, because of not sufficiently high level of compressive residual stress in the TiN deposited by physical deposition method and varied mechanical properties of the thin film and substrate. The residual stress cannot be identified by X-ray technique for amorphous polymer and layer with domains of crystalline TiN. It is assumed that the buffer biocompatible thin film of Au in the TiN/Bionate II material system will alter the evolution of residual stress and, therefore, will allow to determine the residual stress in profilometry studies, and helps to improve toughness of the connection between TiN and Bionate II. The introduction of Au nanocoating in the material system results in bending of the sample and a compressive residual stress in the TiN coating. Results of finite element simulation show improvement of connection between the polymer and $\mathrm{TiN}$, and an increase of compressive residual stress in the coating by introduction of Au nanointerlayer results in reduction of stress and strain in the substrate (close to the boundary between substrate and coating).

\section{Introduction}

The Polish pneumatic ventricular assist device (VAD) [1] is made of a thermoplastic polycarbonate-urethane Bionate II. So far the two-scale model of the device was developed $[2,3]$ and it is still enriched with a new experimental data related to material properties $[4,5]$ and the construction related phenomena observed both in a microscale $[6,7]$, like cracks, fracture [8], and so forth, and in a macroscale, for example, efficiency of the construction shape [9]. The model has already been applied to optimize crucial parameters of the whole construction $[6,9,10]$. Continuing to press ahead, the model development gives hope for further improvements of the VAD construction.

A biocompatible thin film is recommended for surfaces of the VAD, so our construction has a TiN nanocoating deposited by a pulsed laser deposition (PLD) technique. Some disadvantages of this structure were presented elsewhere [11]. The PLD is a low temperature process allowing permanent modification of some properties only in a superficial layer of product, so it can be successfully applied on the polymer substrate. However, this technique similarly as the other physical vapour deposition (PVD) processes usually develops high values of residual stresses [12]. The residual stresses in the layer deposited by PVD methods result from the mismatch of the lattice parameters and of the thermal expansion properties between a thin film and substrate [13]. For the PLD process, kinetic energies of ions and neutral species in an ablation plume can range from a few tenths to several hundred electron volts and are sufficient to modify a stress state of superficial layers through defect formation [14]. The compressive stress state is typical for layers deposited from an unabated energetic plume. The residual stresses in a thin film system can lead to buckling, cracking, void formation, and film debonding [13]. For the room temperature deposition, the stresses easily can reach an unacceptable level [11]. Fortunately, they can be reduced by a selection of process parameters $[15,16]$.

Defect with a dome-shaped topography can be formed during covering of stiff substrates. On the other hand, wrinkle structures are typical for the deposition of soft substrates. The wrinkling is a typical defect related to a high residual stress developed in TiN coatings deposited on polymers such as polycarbonate, polyimide, polyamide, and thermoplastic 
polyurethane $[11,15]$. Wrinkles and nanowrinkles are related to a stress relaxation of the whole structure and can be formed in several superseding structures with an increase of thickness of the deposited film. Some cracks can be formed in the coating when the coating cannot follow the deformation of the substrate surface by elastic or plastic deformation. Cracks can be observed in the coating of easily deformable polymers even for films of thickness of $10 \mathrm{~nm}$ [15].

Different solutions are proposed in the literature to avoid/reduce detrimental effects related to a residual stress. From our point of view the most interesting are those related to an introduction of an intermediate gold layer between a TiN and polymer [17-19], because gold is known as the biocompatible material. It was stated that the gold layer (especially a very thin layer) can increase a toughness of the structure [17] and improve a metal-polymer connection [18]. On the other hand, the gold buffer layer also can change residual stress [19] and does not have isotropic properties [19]. Concluding, it is very difficult to anticipate directly a precise influence of the gold buffer layer on residual stress in the structure.

Experimental and numerical verifications of the effect of gold buffer on the residual stress in the TiN nanocoating deposited on the Bionate II polymer substrate and on the structure properties determined during a microtensile test are the practical goals of the present work. We hope that presented approach will be helpful to design the optimal structure of the VAD and moreover provide methodology for construction of similar structures dedicated for other applications.

\section{Experiments}

The TiN nanocoatings of thicknesses ca. $50 \mathrm{~nm}$ were deposited on the Bionate II substrates. The ablation system uses a Nd:YAG pulsed laser that was applied [16]. The parameters of deposition process were $100 \mathrm{~mJ}$ energy of laser beam, $266 \mathrm{~nm}$ wavelength, $4.2 \mathrm{~J} / \mathrm{cm}^{2}$ fluence, $25^{\circ} \mathrm{C}$ temperature of substrate, $12 \mathrm{~ns}$ pulse duration at a repetition rate of $10 \mathrm{~Hz}$, and 5000 laser shots. For one lot of samples the gold nanocoatings of thickness $5 \mathrm{~nm}$ were deposited as interlayers between the $\mathrm{TiN}$ and Bionate II. The gold was deposited by a magnetron sputtering method with a discharge current $10 \mathrm{~mA}$ and a deposition time $5 \mathrm{~min}$. The interlayers were not imposed for specimens from the second lot of samples. The part of substrate was obscured during deposition, and such area was used for measurements of the deposited thickness. The Dimension Icon PT (by Veeco) atomic force microscopy (AFM) was used for a thickness measurement of the deposited materials. The AFM was also used for roughness measurements ( $R_{a}$ parameter) of the deposited layers which was determined as equal to about $113 \mathrm{pm}$ (for size of area $c a .100 \mathrm{~nm} \times 100 \mathrm{~nm}$ ) and $5.21 \mathrm{~nm}$ and $241 \mathrm{~nm}$ (for sizes of areas $c a .1 \mu \mathrm{m} \times 1 \mu \mathrm{m}$ and $100 \mu \mathrm{m} \times 100 \mu \mathrm{m})$. For polyurethane substrate $R_{a}$ parameter is about $1.74 \mathrm{~nm}$ (for size of area ca. $100 \mathrm{~nm} \times 100 \mathrm{~nm}$ ) and $7.5 \mathrm{~nm}$ and $78.7 \mathrm{~nm}$ (for sizes of areas ca. $1 \mu \mathrm{m} \times 1 \mu \mathrm{m}$ and $100 \mu \mathrm{m} \times 100 \mu \mathrm{m})$. These values are the average arithmetic of the highest and lowest points over the complete 3 dimensional surface, determined for the three sizes of areas. The AFM's images showing the coatings' topography on the selected line of the 3 areas in $3 \mathrm{D}$ are presented in Figure 1. The surface of TiN nanocoating is not regular, as well as the profile connection between the coating and substrate. The approach, which describes in a simplified way the problems associated with the deviation of surface, was developed by international standards [20] and for the TiN deposited on polymer it is similar to a surface roughness described by the second order deviation [20] which can be approximated by a sinusoidal wave and characterized by its parameters (an antinode and a wavelength). For the TiN coating an antinode and a wavelength were equal to $12.5 \mathrm{~nm}$ and $100 \mathrm{~nm}$, respectively. These values were calculated for a surface wave approximated by a sinusoidal wave. Moreover, during measurement it was verified that the coatings were smooth, without cracks, delaminations, and chipping and they were suitable for further experiments.

For residual stress determination the specimens of size $23 * 5 * 0.14 \mathrm{~mm}$ were used. One end of each specimen on distance of $0.2 \mathrm{~mm}$ was free of coatings. The camera pictures of specimen TiN/Au/Bionate II are shown in Figure 2. Deflections were measured using optical profilometer Wyko NT9300 (by Veeco company). Although vertical resolution of measurement was equal to $3 \mathrm{~nm}$, the overall error of the measurement was estimated as equal to $0.05 \mathrm{~mm}$, due to not uniform thickness of the substrate polymer. It was found that deflection of the one-layer specimens was in the range of experimental error, so it was assumed as a nodeflection case. On the other hand, the specimen with the gold buffer layer indicated significant deflection (increase in the specimen highest deflection equal to $0.976 \mathrm{~mm}$ ) and a bending direction indicated presence of a compressive residual stress. This value was used during calculation of the residuals stress level (see Sections 3 and 4.3).

The microtension test of two and three layers materials was performed directly during the Scanning Electron Microscope (SEM) observation. For this purpose, the Hitachi 3500-N SEM with Kammrath and Weiss Gmbh $5 \mathrm{kN}$ tensile/compression module was applied. Tested specimens with rectangular shape of dimensions $4.15 * 6.76 * 32.6 \mathrm{~mm}$ were used. During tensile tests the samples were elongated by steps, and tensile force in the range from 0 to $40 \mathrm{~N}$ and elongation from 0 to $132 \mu \mathrm{m}$ were applied. After each step of elongation the surface of deformed thin film was observed using SEM (magnification from 600 to $6000 \mathrm{x}$ ) in order to detect cracks appearance. Behavior of the coating during tensile was modeled using the finite elements (FE) in the authors' codes. Methodology and selected results were presented in Section 4.

\section{Residual Stress}

The well-known experimental methods of residual stress measurement, including the X-ray methods [21], are useful, but they have some disadvantages: (a) they give only average and local stresses in a volume; (b) they cannot provide a stress 


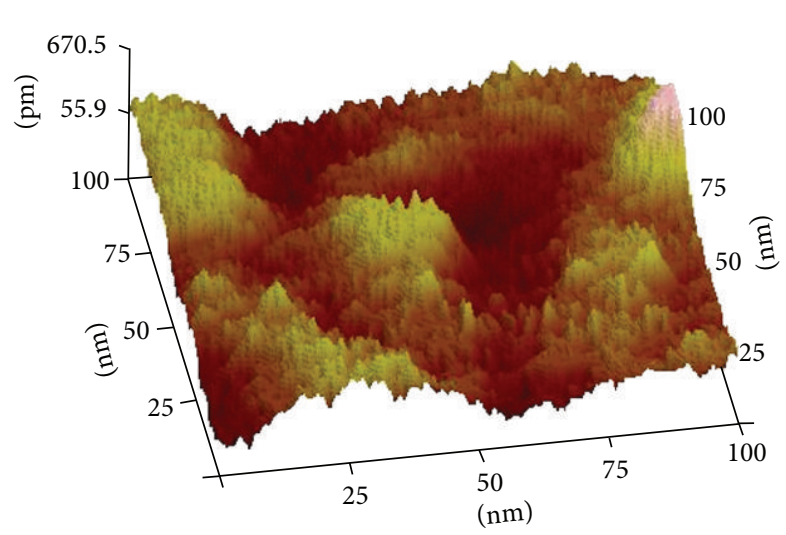

(a)

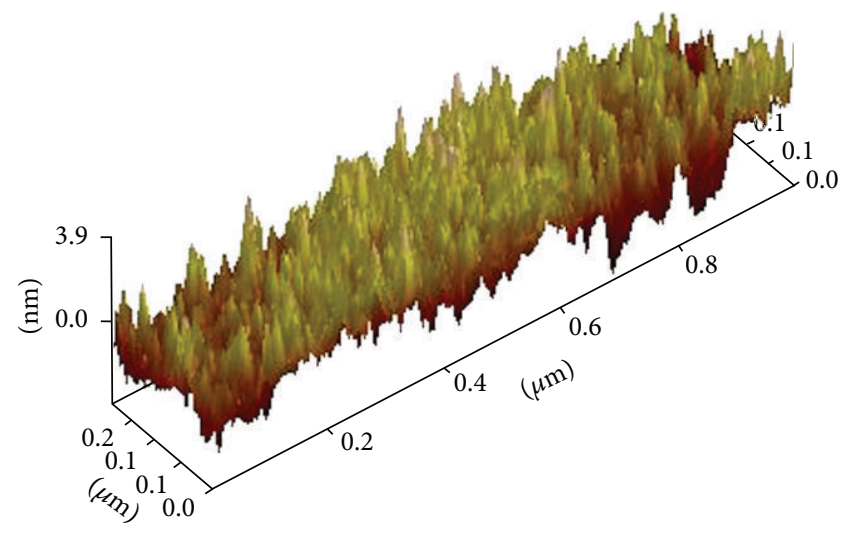

(b)

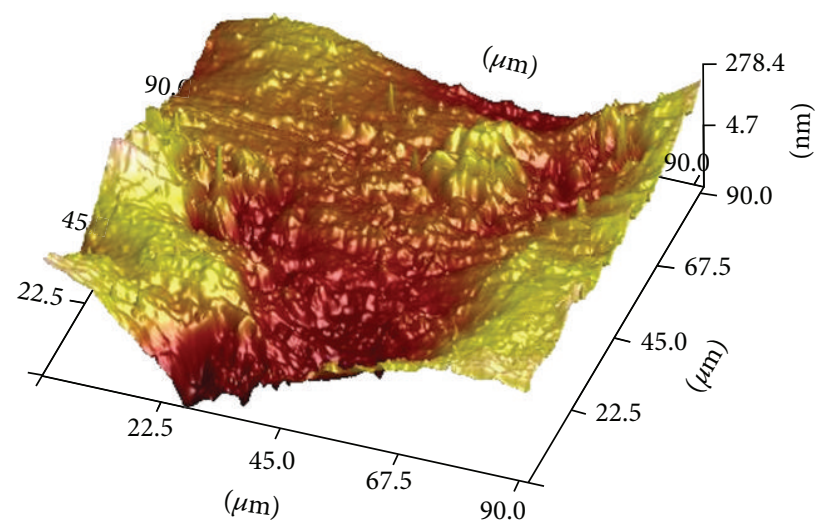

(c)

Figure 1: The AFM's images showing coatings' topography on a selected line of areas in 3D: (a) $100 \mathrm{~nm} \times 100 \mathrm{~nm}$, (b) $1 \mu \mathrm{m} \times 1 \mu \mathrm{m}$, and (c) $100 \mu \mathrm{m} \times 100 \mu \mathrm{m}$.

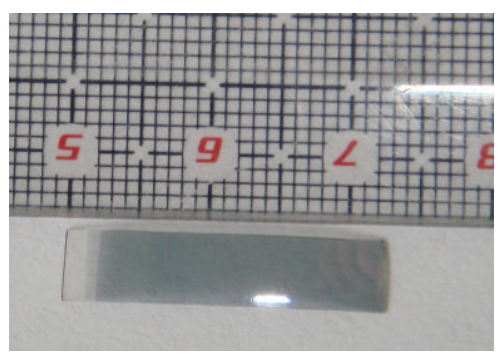

(a)

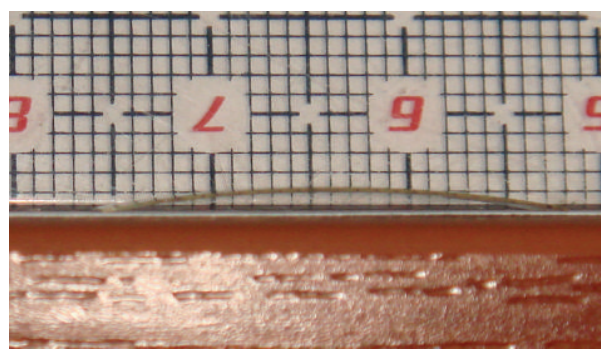

(b)

Figure 2: Camera pictures of the specimen TiN/Au/Bionate II taken at (a) the top of the specimen and (b) the side of the specimen.

variation, distribution, and directions in a thin film system during fabrication; (c) they cannot reveal stress discontinuity across individual layers. Measurements of a diffraction peak displacement and broadening can be used for determination of stresses present in the near surface layers of the crystalline materials [22, 23]. For such materials in-depth stress gradient can be analysed using of grazing incidence geometry of diffraction $[24,25]$. However, these methods are dedicated to well-crystalline materials providing sufficiently strong diffraction peaks [26]. It was checked that such conditions are not fulfilled in the case of layers analysed in the present work, and, therefore, the stress cannot be measured using the X-ray diffraction.

However, surface stress can cause bending of a thin object, and this effect can be used for a determination of the stress level. Such method (referred to as the curvature measurement method (CMM)) has already been successfully used for the determination of stress in titanium nitride coating on a steel [27], on the WC-Co substrate, and for the Au coating on Si substrate [28]. A two-layer bimaterial beam or plate specimen is usually used for CMM and the curvature is induced due to a change in initial stresses when the specimen is released from 


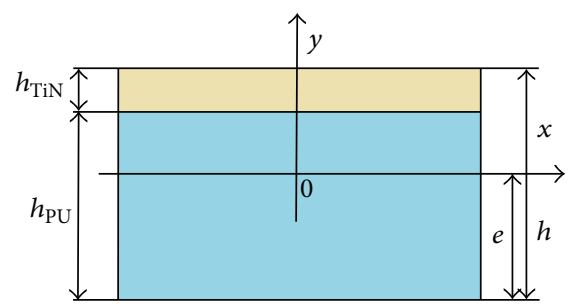

FIGURE 3: Sketch of the sample TiN/Bionate II and parameters used in analytical model of residual stress.

constraints imposed during the stress source processing. In the case of a thick beam specimen with a very thin coating, the thin-film approximation can be applied and Stoney's formula can be used for relation from the curvature to residual stress in the coating [29]. However, in this case the curvature tends to be small and difficult to be measured reliably. In order to increase deflections and sensitivity of measurements, a thin substrate should be used; conditions for the Stoney's approximation are not fulfilled and appropriate models have to be developed to relate the measured curvature to the residual stress (e.g., the Timoshenko model [30, 31], the model of Suhir [32,33], or the finite element Schajer's integral methodology [28]). Some models were also developed for the multilayered structures [34-36]. The model developed by the Timoshenko is relatively simple and has no restriction on thickness of layers in the analyzed structure, so it is used in the present work. The schematic sketch of the sample and parameters used in the analytical model of residual stress is shown in Figure 3.

The interpretation of results of experiment was based on methodology developed for determination of residual stress in layers considering the observed deflection of samples [30, 31]. It is assumed that in the moment of deflection of sample the material is in an elastic state. The formulas (1) and (2) are written for composition of materials TiN and Bionate II, and they are taken from works $[30,31]$. The formulas (3) and (4) are written for composition of materials $\mathrm{TiN}, \mathrm{Au}$, and Bionate II based on the same assumptions as it is in formulas (1) and (2). In case, when the thickness of $\mathrm{Au}$ thin film is small (about 0.1 times smaller than the thickness of TiN), the interpretation of results can be done by using formulas (1) and (2). The formulas (5) and (6) are helpful to obtain the volumetric strain and mean stress in $\mathrm{TiN}$, which are necessary in a FE formulation of the problem. Consider

$$
\begin{gathered}
e=\frac{E_{\mathrm{TiN}}\left(h^{2}-h_{\mathrm{PU}}^{2}\right)+E_{\mathrm{PU}} h_{\mathrm{PU}}^{2}}{2\left(E_{\mathrm{PU}} h_{\mathrm{PU}}+E_{\mathrm{TiN}} h_{\mathrm{TiN}}\right)}, \\
\varepsilon_{x \mathrm{TiN}}=\frac{8 f}{3 L^{2}}\left(\frac{E_{\mathrm{TiN}}\left((h-e)^{3}-\left(h_{\mathrm{Pu}}-e\right)^{3}\right)}{E_{\mathrm{TiN}} h_{\mathrm{TiN}}\left(h_{\mathrm{PU}}-e+(1 / 2) h_{\mathrm{TiN}}\right)}\right. \\
\left.+\frac{E_{\mathrm{Pu}}\left(\left(h_{\mathrm{PU}}-e\right)^{3}+e^{3}\right)}{E_{\mathrm{TiN}} h_{\mathrm{TiN}}\left(h_{\mathrm{PU}}-e+(1 / 2) h_{\mathrm{TiN}}\right)}\right),
\end{gathered}
$$

$$
\begin{gathered}
e=\frac{E_{\mathrm{PU}} h_{\mathrm{PU}}^{2}+E_{\mathrm{Au}}\left(\left(h_{\mathrm{PU}}+h_{\mathrm{Au}}\right)^{2}-h_{\mathrm{PU}}^{2}\right)}{2\left(E_{\mathrm{PU}} h_{\mathrm{PU}}+E_{\mathrm{Au}} h_{\mathrm{Au}}+E_{\mathrm{TiN}} h_{\mathrm{TiN}}\right)} \\
+\frac{E_{\mathrm{TiN}}\left(\left(h_{\mathrm{PU}}+h_{\mathrm{Au}}+h_{\mathrm{TiN}}\right)^{2}-\left(h_{\mathrm{PU}}+h_{\mathrm{Au}}\right)^{2}\right)}{2\left(E_{\mathrm{PU}} h_{\mathrm{PU}}+E_{\mathrm{Au}} h_{\mathrm{Au}}+E_{\mathrm{TiN}} h_{\mathrm{TiN}}\right)}, \\
\varepsilon_{x \mathrm{TiN}}=\frac{8 f}{3 L^{2}}\left(\frac{E_{\mathrm{TiN}}\left((h-e)^{3}-\left(h_{\mathrm{Pu}}+h_{\mathrm{Au}}-e\right)^{3}\right)}{E_{\mathrm{TiN}} h_{\mathrm{TiN}}\left(h_{\mathrm{PU}}+h_{\mathrm{Au}}-e+(1 / 2) h_{\mathrm{TiN}}\right)}\right. \\
+\frac{E_{\mathrm{PU}}\left(\left(h_{\mathrm{PU}}-e\right)^{3}+e^{3}\right)}{E_{\mathrm{TiN}} h_{\mathrm{TiN}}\left(h_{\mathrm{PU}}+h_{\mathrm{Au}}-e+(1 / 2) h_{\mathrm{TiN}}\right)} \\
\left.+\frac{E_{\mathrm{Au}}\left(\left(h_{\mathrm{PU}}+h_{\mathrm{Au}}-e\right)^{3}-\left(h_{\mathrm{PU}}-e\right)^{3}\right)}{E_{\mathrm{TiN}} h_{\mathrm{TiN}}\left(h_{\mathrm{PU}}+h_{\mathrm{Au}}-e+(1 / 2) h_{\mathrm{TiN}}\right)}\right) \\
\varepsilon_{0 \mathrm{TiN}}=\frac{2 \varepsilon_{x \mathrm{TiN}}-v_{\mathrm{TiN}} \varepsilon_{x \mathrm{TiN}}}{3} \varepsilon_{x \mathrm{TiN}}\left(\frac{2-v_{\mathrm{TiN}}}{3}\right),
\end{gathered}
$$

where $e$ is center of gravity with respect to properties; $h, h_{\mathrm{PU}}$, $h_{\mathrm{Au}}$, and $h_{\mathrm{TiN}}$ are thicknesses of the whole sample, Bionate II, gold, and titanium nitride; $f$ is a deflection of the sample in profilometric studies; $L$ is length of sample; $\varepsilon_{x \mathrm{TiN}}$ is strain component in the $X$ direction in the TiN nanocoating; $\sigma_{0 T i N}$ is a mean stress in the TiN; $\varepsilon_{0 \mathrm{TiN}}$ is a mean strain in the TiN; $E_{\mathrm{PU}}, E_{\mathrm{Au}}$, and $E_{\mathrm{TiN}}$ are Young's moduli of the Bionate II, gold, and titanium nitride; $v_{\mathrm{TiN}}$ is Poisson's ratio of the titanium nitride.

\section{Tension Test}

The typical literature reports present the approach to experimental microtension test, in which the strain-stress curves and the SEM's microphotographs of specimens are obtained, for example, in [37-39]. The second group of literature studies is dedicated to numerical modelling of the in situ SEM's microtension/microcompression test, in which a finite element method (FEM) [40] and discrete dislocation dynamics (DD) [41] are applied. The numerical and experimental approaches are coupled in all of the cited works [40, 41]. The recommended numerical methods (FEM and DD) are combined in the latest works [42] and they were dedicated to problems of mechanical behaviour of crystals from microto nanoscales. Summarizing, the literature research shows that experimental in situ SEM's microtension test provides detailed data especially for a fracture analysis in a microscale. The last fact is often examined in the literature for materials of the crystal plasticity problems. The same trend is observed in the numerical research of the tests inspired by the in situ SEM's microtension/microcompression tests. The FEM and DD methods are used to solve not only problems of a fracture in a microscale, but a nano scale is also analysed. 
4.1. Observations. The selected results reached in the in situ SEM's microtension test for $50 \mathrm{~nm}$ of the TiN at forces 8 , 15 , and $40 \mathrm{~N}$ are shown in Figure 4. The deposited films crack only after an external forced deformation and the cracks are arranged at an angle of $75-85^{\circ}$ to the stretching direction. There are some small cracks on the surface of coating at the initial stage of deformation (tensile force $14 \mathrm{~N}$, elongation about $2 \mathrm{um}$ ). When the sample is stretched at about $0.2 \mathrm{~mm}$, the number of cracks begins to increase rapidly. When the sample is stretched at exactly $0.2 \mathrm{~mm}$, the entire sample surface is covered with cracks. It should be noted that an extension of $50 \mathrm{~nm}$ of the TiN of about $0.2 \mathrm{~mm}$ causes very big deformation. The numerous cracks occur at the stretching of several $\mu \mathrm{m}$. The cracks propagate in the perpendicular direction to the main cracks and are caused by a shrink and a deformation of substrate in the direction perpendicular to the stretching. The justification of cracking of the TiN coatings is shown, for example, in the work [15]. The substrate-coating compound system always tends to reduce the overall strain energy. If the substrate material is deformable like the polymer substrates, the huge difference in elastic moduli trigger huge deformation of the surface. Wrinkling has been suggested as a mode of common deformations of the substrate (surface) and the film in such situations. Wrinkling is described as the formation of sinusoidal buckles on the surface, which does not lose their adhesion to the substrate (which distinguishes it from a buckling). Thus, the main deformation mechanisms in wrinkling are bending of the substrate or of the near-surface region of the substrate (depending on the elasticity of the substrate material) together with the covering coating.

4.2. Modeling. The macroscale analysis on an inner surface of the Religa Heart Ext blood chamber (a strain is acquired from the macroscale FE model) was used to find the areas with the greatest tendency to failure. The FE elements with the maximum strain and stress were located between the two connectors in [9] on the inner surface of the blood chamber. These results were also examined in the developed microscale model [6]. The same microscale model enriched with boundary conditions taken from the experimental microtension test is developed in the present work. The SEM's results represent a mean strain in the direction of elongation $(X)$ and it is the boundary condition in the microscale model of the test (for a representative volume element, RVE). The microscale models of the TiN/Au/polymer and the TiN/polymer developed in the present paper have irregularities (roughness) due to the TiN nanocoating and they are based on the AFM's results. The coating is represented by a periodic function [20] with three key parameters: an amplitude, a wavelength, and a thickness. The micromodel incorporates the experimental parameters: a residual stress $(690 \mathrm{MPa})$, shape parameters of the coating wave's characteristics, material models of the TiN and $\mathrm{Au}$ coatings, and the polymer.

The mechanical properties of the material system $\mathrm{TiN} / \mathrm{Au} /$ Bionate II are assumed as follows.

(a) The bilinear [43], elastic-plastic material model of the TiN nanocoating is described by the parameters identified in [5]: $\varepsilon_{1}=0.009, \sigma_{1}=2,614 \mathrm{MPa}, \varepsilon_{2}=0.166$, and $\sigma_{2}=9,107 \mathrm{MPa}$, and the Poisson's ratio is 0.25 .

(b) The Hollomon's material model of the Bionate II at room temperature is identified in [8]: $36.45 \varepsilon^{0.72}$ based on results given by the Foundation of Cardiac Surgery Development in Poland, and the Poisson's ratio is 0.4.

(c) The properties of $\mathrm{Au}$ coating given in [19] are the average Young's modulus 132.73 GPa and the Poisson's ratio 0.3 .

The RVE is composed of the polymer and the TiN and/or the Au nanocoating. The nonlinearity of the mechanical properties of the TiN coating, Au coating, and the polymer are observed. Thus, an elastic-plastic and a nonlinear elastic material models, as well as their corresponding theories, are used in the computations. The microscale boundary problem, which included the unloading process, is solved by the FE micromodel. The initial stress $\left\{\sigma_{0 \text { res }}\right\}$ in the TiN nanocoating is applied in the FE formulation. The relationship between the stresses and strains is established using a matrix (vector) definition:

$$
\left\{\sigma^{m}\right\}=\left[D^{m}\right]\left\{\varepsilon^{m}\right\}-\left\{\sigma_{0 \text { res }}^{m}\right\},
$$

where $\left\{\sigma_{0 \text { res }}^{m}\right\}$ is residual stress; $\left\{\sigma^{m}\right\}$ and $\left\{\varepsilon^{m}\right\}$ are stress and strain tensors in a vector format.

The variational principle of the nonlinear elastic and elastic-plastic theories leads to the following functional form for the finite element $e$ in the RVE:

$$
\begin{aligned}
W= & \int_{V_{e}} \frac{1}{2}\left\{U^{m}\right\}^{T}[B]^{T}\left[D^{m}\right][B]\left\{U^{m}\right\} d V \\
& -\int_{V_{e}}\left\{U^{m}\right\}^{T}[B]^{T}\left\{\bar{\sigma}_{0 \text { res }}^{m}\right\} d V-\int_{S_{e}}\left\{U^{m}\right\}^{T}[\bar{N}]^{T}\left\{p^{m}\right\} d S,
\end{aligned}
$$

where $\left\{U^{m}\right\}$ is a nodal displacement vector in the elements; $\bar{\sigma}_{0 \text { res }}^{m}$ is an experimental value of the residual stress in the current finite element $e$ (the residual stress was introduced in the TiN nanocoating in the model).

The effective Young's modulus is used in the elastic zone (instead of the Young's modulus) to linearise the function in (7) for a nonlinear problem:

$$
E_{\mathrm{eff}}^{m}=\frac{\sigma_{i}^{m}}{\varepsilon_{i}^{m}},
$$

where $\sigma_{i}^{m}$ is an effective stress and $\varepsilon_{i}^{m}$ is an effective strain.

The stiffness matrix $[K]$ and the load vector $\{F\}$ are established in the forms

$$
\begin{gathered}
{\left[K_{e}^{m}\right]=\int_{V_{e}}[B]^{T}\left[D^{m}\right][B] d V} \\
\left\{F_{e}^{m}\right\}=-\int_{V_{e}}[B]^{T}\left\{\bar{\sigma}_{0 \text { res }}^{m}\right\} d V-\int_{S}[\bar{N}]^{T}\left\{p^{m}\right\} d S .
\end{gathered}
$$

The periodic boundary conditions (PBC) are used and the cinematic boundary conditions are applied in the direction 


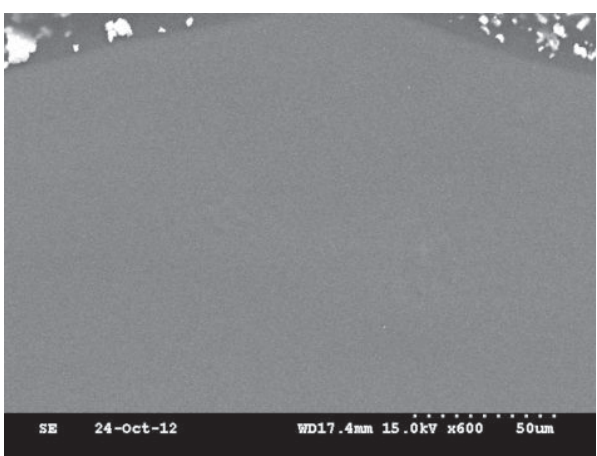

(a)

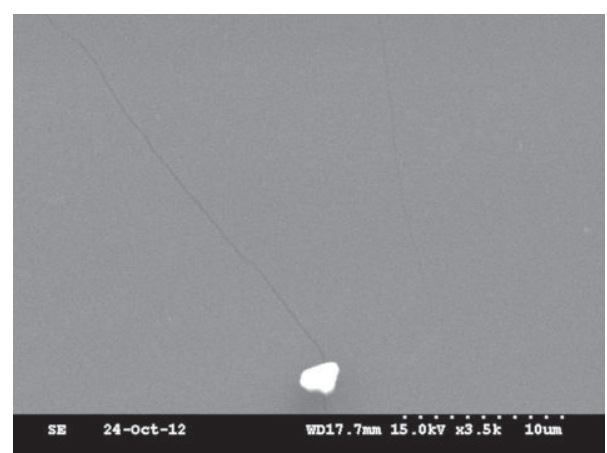

(b)

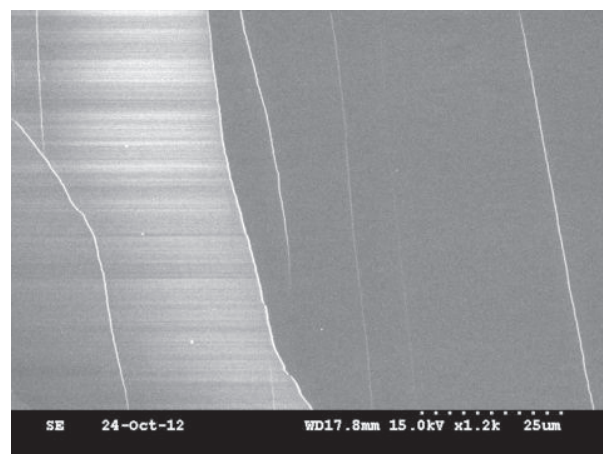

(c)

FIGURE 4: The SEM's image of $50 \mathrm{~nm}$ of TiN coating stretched at (a) $8 \mathrm{~N}$, (b) $15 \mathrm{~N}$, and (c) $40 \mathrm{~N}$.

of tension. The deformation in a direction of tension $\varepsilon_{1}^{M}$ (the first principal strain of the strain tensor) obtained in the in situ SEM's microtension test as the mean $X$-strain is used as a boundary condition for the RVE. Strain $\varepsilon_{2}^{M}$ (the second principal strain of the strain tensor) taken from the in situ SEM's microtension test as the mean $Y$-strain is introduced in the microscale model. Therefore, the $3 \mathrm{D}$ boundary problem of the RVE deformation is transformed to the 2D plane strain problem with a prescribed value of the strain $\varepsilon_{2}^{M}$.

The two FE models of microtension test corresponding to two samples TiN/Bionate II and $\mathrm{TiN} / \mathrm{Au} /$ Bionate were developed. The following compositions of material layers were applied in the models: (1) $50 \mathrm{~nm}$ of TiN, $5 \mathrm{~nm}$ of Au, and $1000 \mathrm{~nm}$ of Bionate II and (2) $55 \mathrm{~nm}$ of TiN and $1000 \mathrm{~nm}$ of Bionate II. The FE models used to solve the boundary problem are composed of 13320 nodes. The boundary conditions, materials' layers, a normal strain $\varepsilon_{x x}$, and a mesh applied in the first FE model are shown in Figure 5. The same boundary conditions and a FE mesh were used in the second model.

4.3. Identification of Residual Stress by Analytical Model. According to the set of parameters introduced in (1)-(6) and their values: $E_{\mathrm{PU}}=200 \mathrm{MPa}, \nu_{\mathrm{Pu}}=0.45, E_{\mathrm{TiN}}=290.4 \mathrm{GPa}$, $\nu_{\mathrm{TiN}}=0.25, E_{\mathrm{Au}}=1.3 \mathrm{GPa}, \nu_{\mathrm{Au}}=0.3, f=0.976 \mathrm{~mm}$, and $L=23 \mathrm{~mm}$, the residual stress and volumetric strain calculated in the analytical model (3)-(6) in the TiN are $\sigma_{0}=690 \mathrm{MPa}$ and $\varepsilon_{0}=0.0012$ for the material system $\mathrm{TiN} / \mathrm{Au} /$ Bionate II.
4.4. Comparison of FE Models of Microtension Test for Samples TiN/Au/PU and TiN/PU. Based on settings of the experimental microtension tests, the corresponding numerical models of the tests were prepared in a microscale. The simulations were performed for the initial, middle, and final stages of the test, which corresponds to the forces $8 \mathrm{~N}\left(\varepsilon_{x \mathrm{TiN}}=\right.$ $0.0011903), 15 \mathrm{~N}\left(\varepsilon_{x \mathrm{TiN}}=0.0028368\right)$, and $40 \mathrm{~N}\left(\varepsilon_{x \mathrm{TiN}}=\right.$ $0.0109978)$. These stages were selected because significant changes on the surface of samples were observed in relation to the previous steps of deformation.

The results for the two FE micromodels of samples TiN/Au/PU and TiN/PU for the three loadings (forces: 8, 15 , and $40 \mathrm{~N}$; critical loading) are presented in Figures 6-14. The distributions of effective strain $\varepsilon_{i}$ are shown in Figures 8,11 , and 14 , the distributions of shear stress $\sigma_{x y}$ in $\mathrm{MPa}$ are shown in Figures 7, 10, and 13, and the distributions of normal stress $\sigma_{x x}$ in $\mathrm{MPa}$ are shown in Figures 6, 9, and 12. The exact values of maximum and minimum values of effective strain, normal stress, and shear stress computed in the FE models of microtension test for samples: TiN/Au/Bionate II and TiN/Bionate II, are plotted in Figure 15 and they are taken from the results presented in Figures 6-14.

The qualitative analysis of distributions of shear stress $\sigma_{x y}$ in the tested samples shows that the maximum of compressive shear stress on the boundary between coating and substrate is located in the ascending portion of wave of coating. Contrary, the minimum of tensile shear stress $\sigma_{x y}$ on the boundary between coating and substrate is located in the descending portion of wave of coating under all loadings. The second 


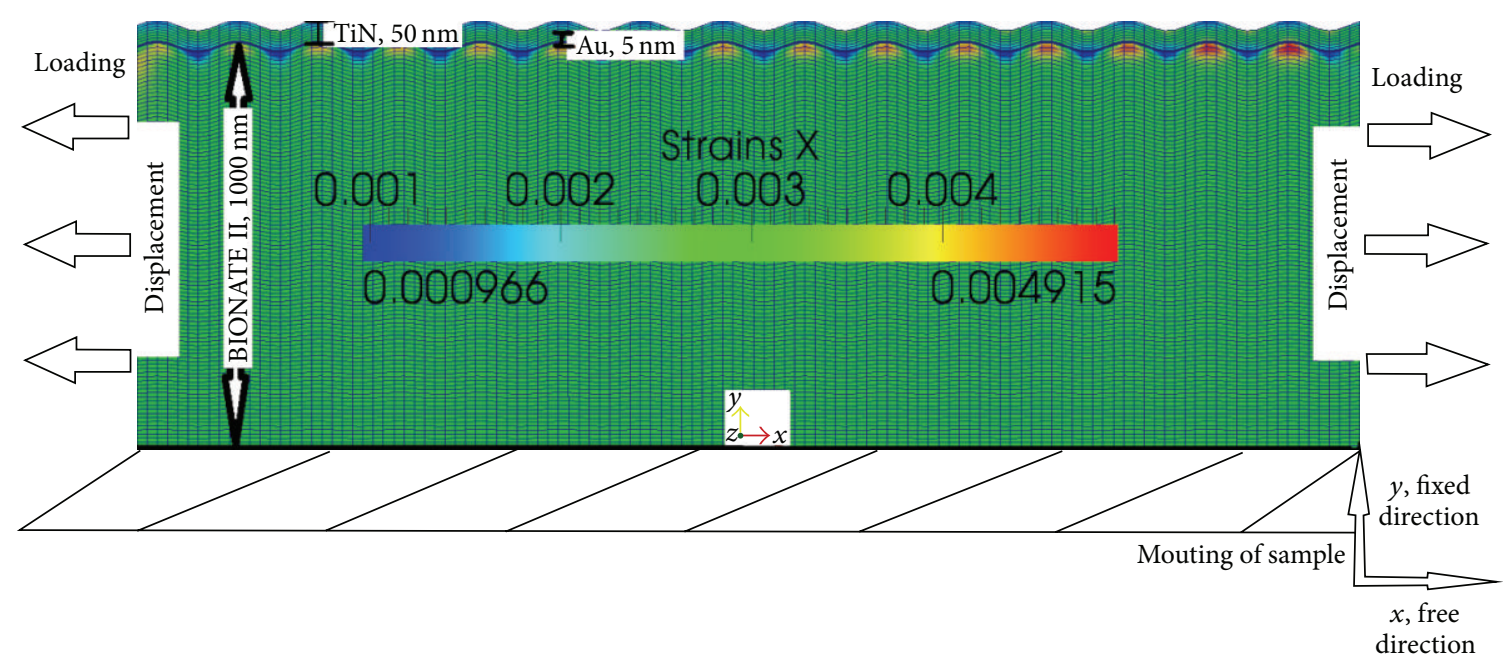

FIGURE 5: The boundary conditions, a normal strain $\varepsilon_{x x}$, and a mesh used in the FE models of microtension test.

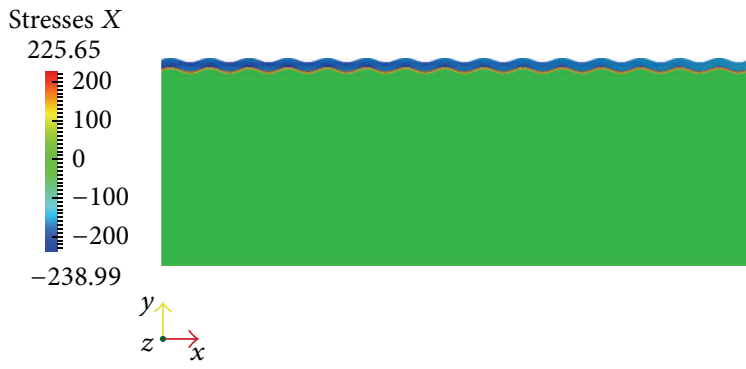

(a)

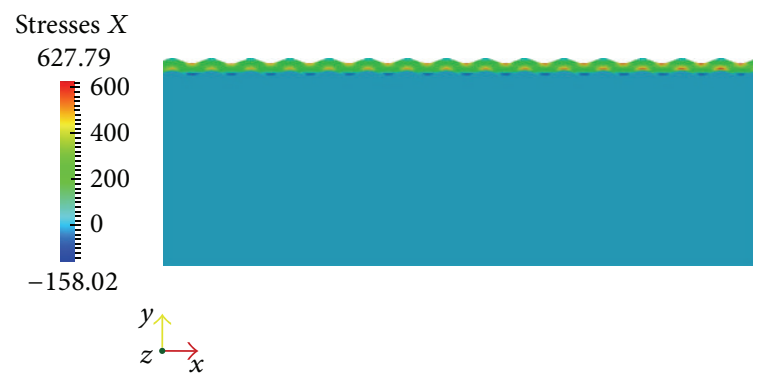

(b)

FIgUre 6: A normal stress $\sigma_{x x}$ in MPa for the FE model of samples: (a) TiN/Au/PU and (b) TiN/PU, stretched at $8 \mathrm{~N}$ in microtension test.

location of maximum and minimum shear stress $\sigma_{x y}$ appears under the middle loading and it is visible in the center of the TiN coating. The third location of maximum and minimum shear stress $\sigma_{x y}$ appears under the biggest loading and it reaches the surface of the sample. The absolute values of compressive and tensile shear stresses $\sigma_{x y}$ in the same type of tested samples are almost equal for each loading. The absolute values of compressive and tensile shear stresses $\sigma_{x y}$ are $50 \%$ bigger in the samples without Au coating under the smallest and the biggest loadings. The absolute values of compressive and tensile shear stresses $\sigma_{x y}$ are twice bigger in the samples without Au coating under the middle loading.

The qualitative analysis of distributions of normal stress $\sigma_{x x}$ for both samples shows that the character of distributions is similar under all loadings. The distribution of normal stress $\sigma_{x x}$ in the substrate is homogeneous under all loadings. The distribution of normal stress $\sigma_{x x}$ is heterogeneous in the coating and it is caused by the wave character of coating. However, the homogenous distribution of normal stress $\sigma_{x x}$ in the coating is observed in the sample with Au under the lowest loading. In this case, the maximum of compressive normal stress $\sigma_{x x}$ is located in the Au coating and the maximum of tensile normal stress $\sigma_{x x}$ is computed in the TiN coating. For the other simulation, the wave character of coatings is visible in the distributions of normal stress $\sigma_{x x}$. Hence, the maximum of tensile normal stress $\sigma_{x x}$ is located in the nodes of wave on the boundary between coating and substrate and in the amplitude of wave on the surface of sample. On the other hand, the maximum of compressive normal stress $\sigma_{x x}$ appears in the amplitude of wave on the boundary between coating and substrate and in the nodes of wave on the surface of sample. The size of areas of maximum of compressive and tensile normal stresses $\sigma_{x x}$ depends on the value of loading. The biggest widening of areas of maximum of compressive normal stress $\sigma_{x x}$ under the biggest loading is observed for both samples. The quantitative analysis of maximum of compressive and tensile normal stress $\sigma_{x x}$ for both samples under all loadings shows that the absolute values of normal stress $\sigma_{x x}$ are several times smaller in the samples with Au coating. The absolute value of maximum of compressive normal stress $\sigma_{x x}$ is also several times bigger in the sample with $\mathrm{Au}$ coating than the absolute value of maximum of tensile normal stress $\sigma_{x x}$. The same absolute values of maximum of compressive and tensile normal stresses $\sigma_{x x}$ are computed for sample with $\mathrm{Au}$ under the lowest loading. The smallest percentage of variation between maximum values of compressive normal stress $\sigma_{x x}$ for both samples is under the biggest loading. The comparable 


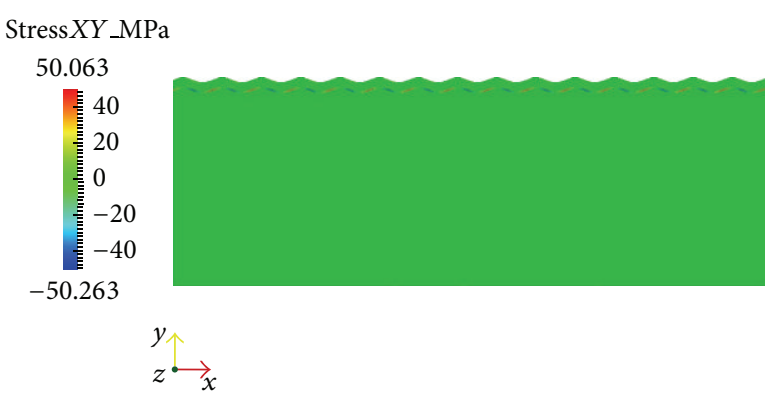

(a)

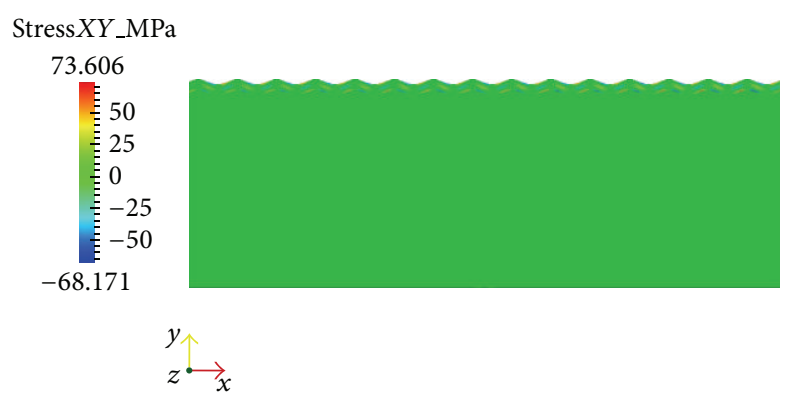

(b)

FIGURE 7: A shear stress $\sigma_{x y}$ in MPa for the FE model of samples: (a) TiN/Au/PU and (b) TiN/PU, stretched at $8 \mathrm{~N}$ in microtension test.

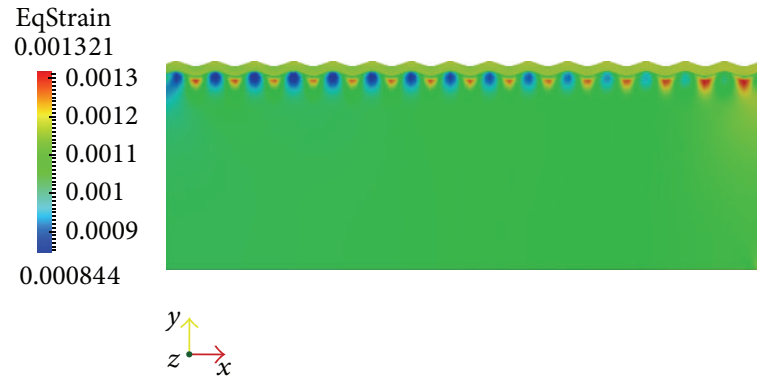

(a)

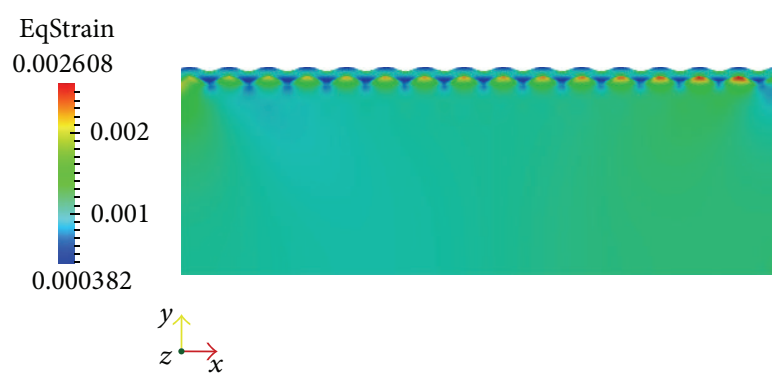

(b)

Figure 8: An effective strain $\varepsilon_{i}$ for the FE model of samples: (a) TiN/Au/PU and (b) TiN/PU, stretched at $8 \mathrm{~N}$ in microtension test.

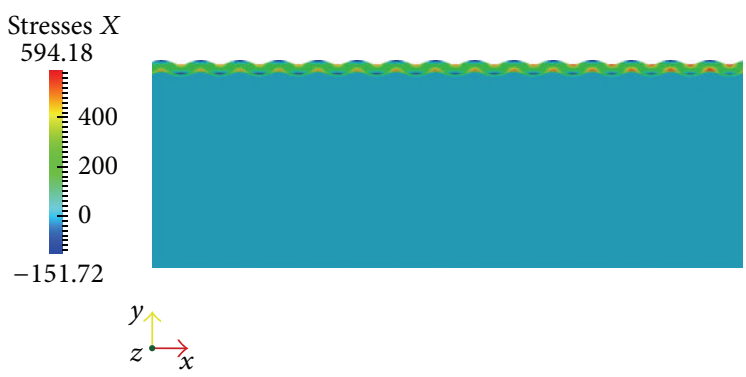

(a)

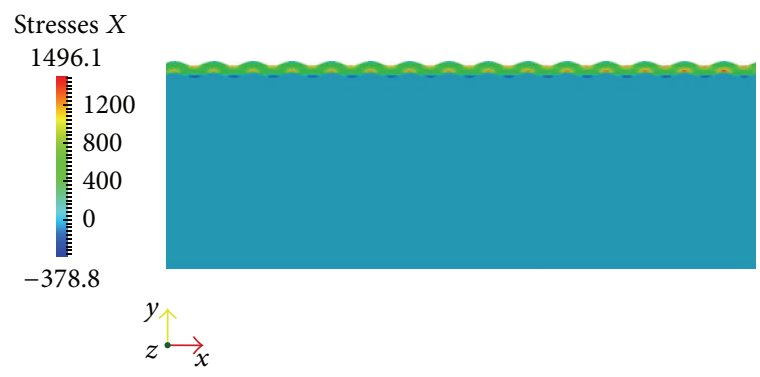

(b)

FIGURE 9: A normal stress $\sigma_{x x}$ in MPa for the FE model of samples: (a) TiN/Au/PU and (b) TiN/PU, stretched at $15 \mathrm{~N}$ in microtension test.

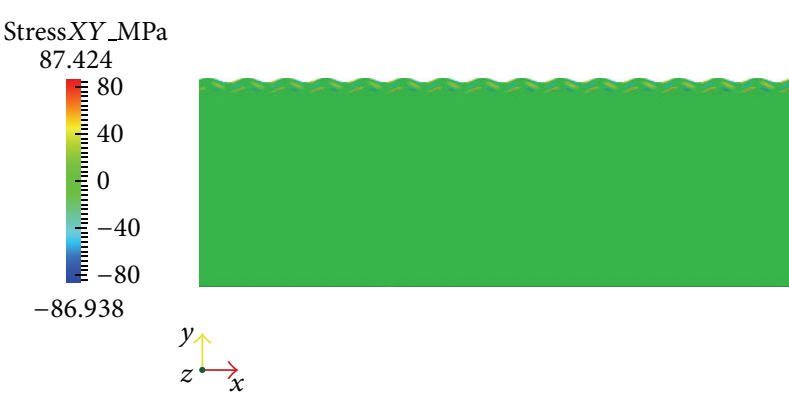

(a)

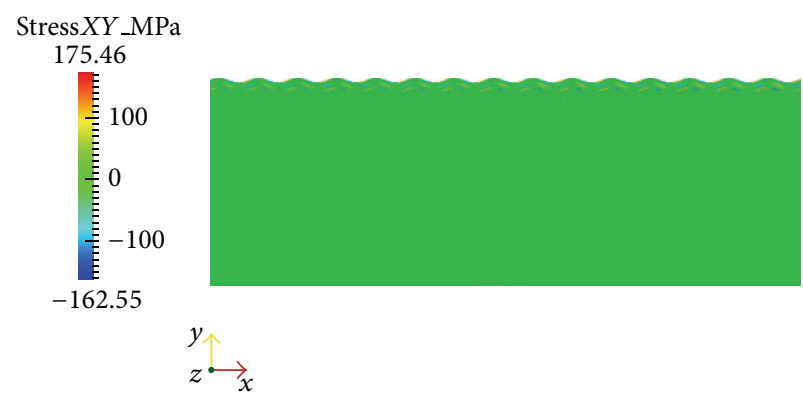

(b)

Figure 10: A shear stress $\sigma_{x y}$ in MPa for the FE model of samples: (a) TiN/Au/PU and (b) TiN/PU, stretched at $15 \mathrm{~N}$ in microtension test. 


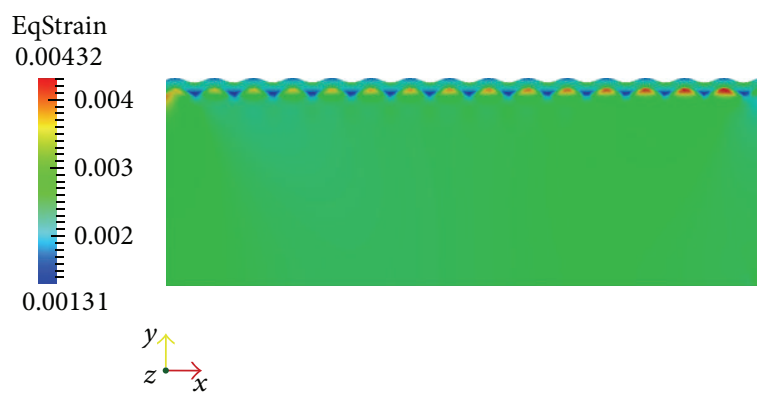

(a)

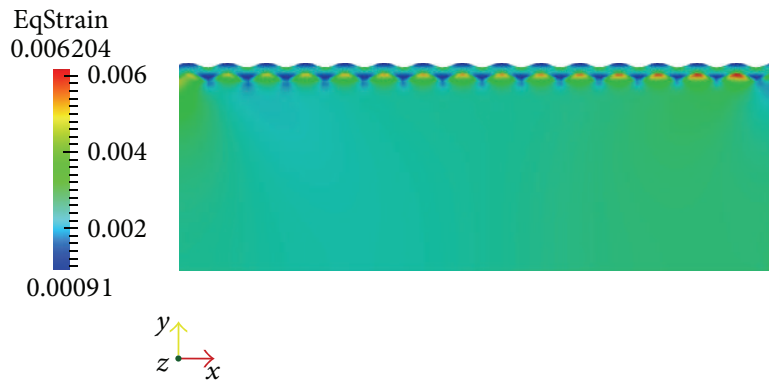

(b)

FIGURE 11: An effective strain $\varepsilon_{i}$ for the FE model of samples: (a) TiN/Au/PU and (b) TiN/PU, stretched at $15 \mathrm{~N}$ in microtension test.

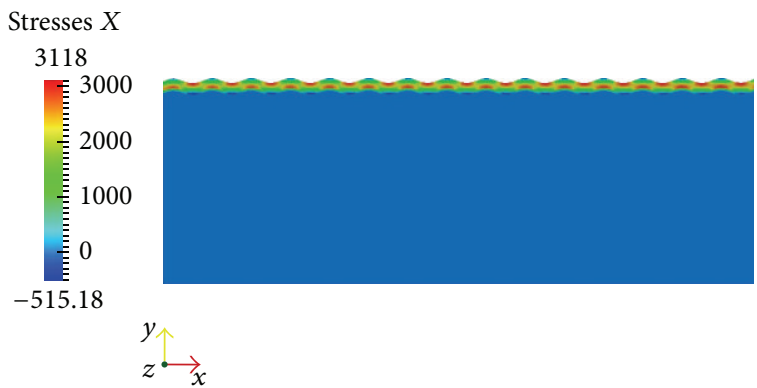

(a)

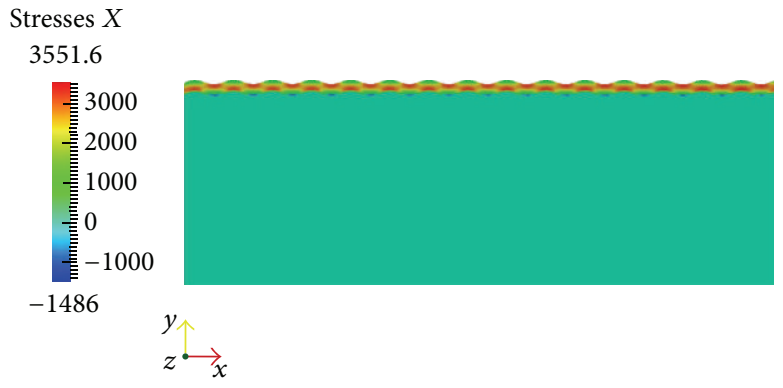

(b)

Figure 12: A normal stress $\sigma_{x x}$ in MPa for FE model of samples: (a) TiN/Au/PU and (b) TiN/PU, stretched at $40 \mathrm{~N}$ in microtension test.

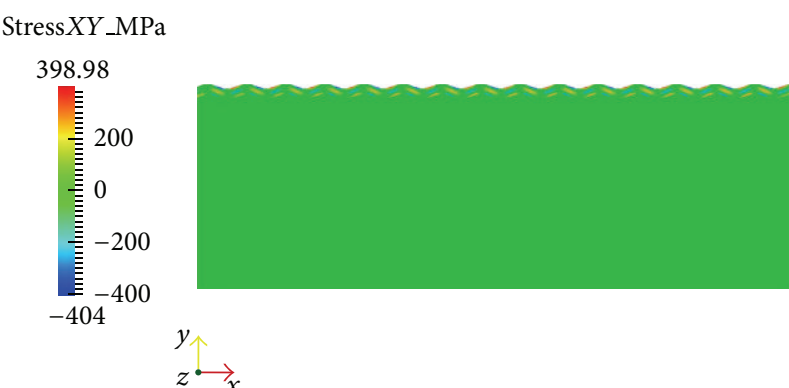

(a)

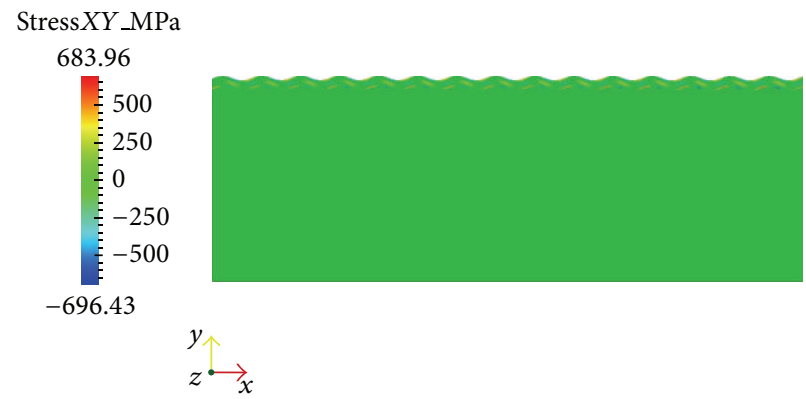

(b)

FIgUre 13: A shear stress $\sigma_{x y}$ in MPa for the FE model of samples: (a) TiN/Au/PU and (b) TiN/PU, stretched at $40 \mathrm{~N}$ in microtension test.

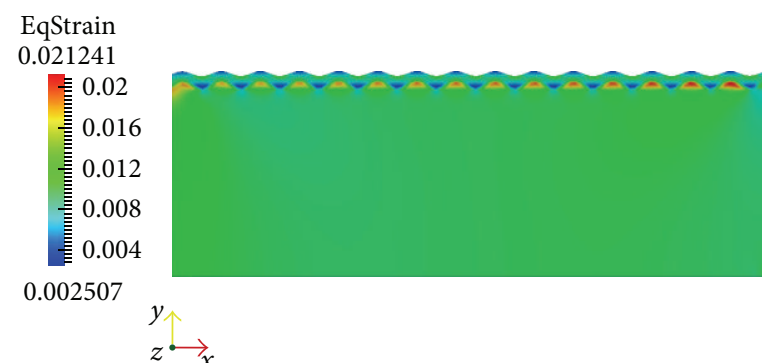

(a)

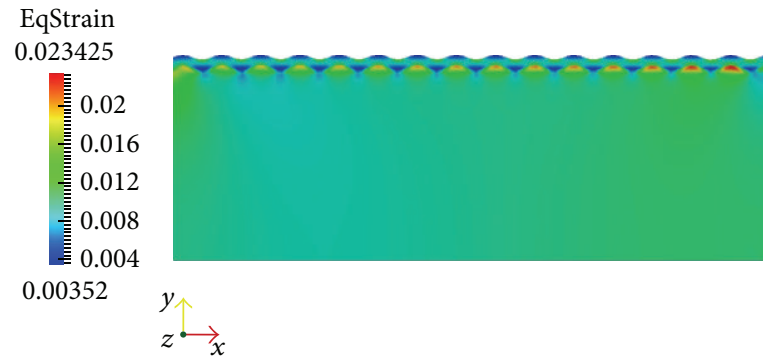

(b)

FIgure 14: An effective strain $\varepsilon_{i}$ for the FE model of samples: (a) TiN/Au/PU and (b) TiN/PU, stretched at $40 \mathrm{~N}$ in microtension test. 


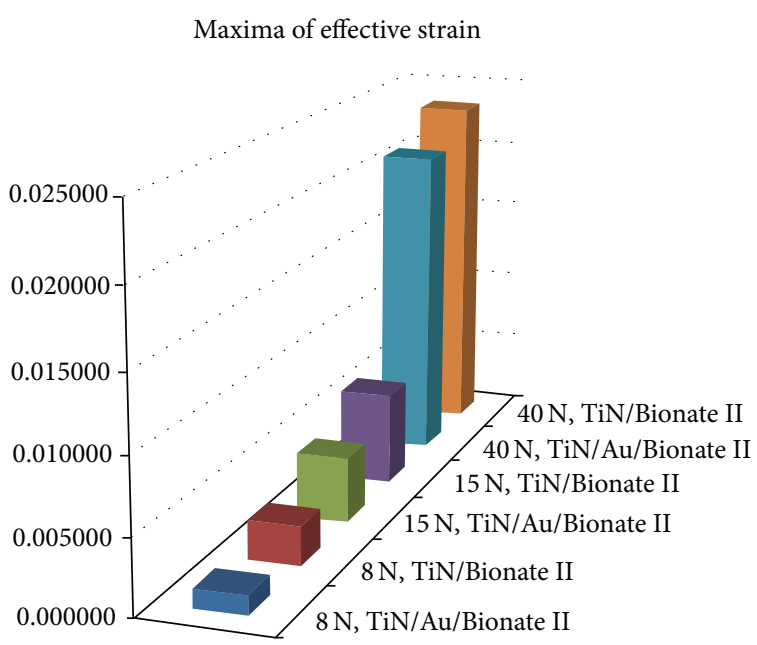

(a)

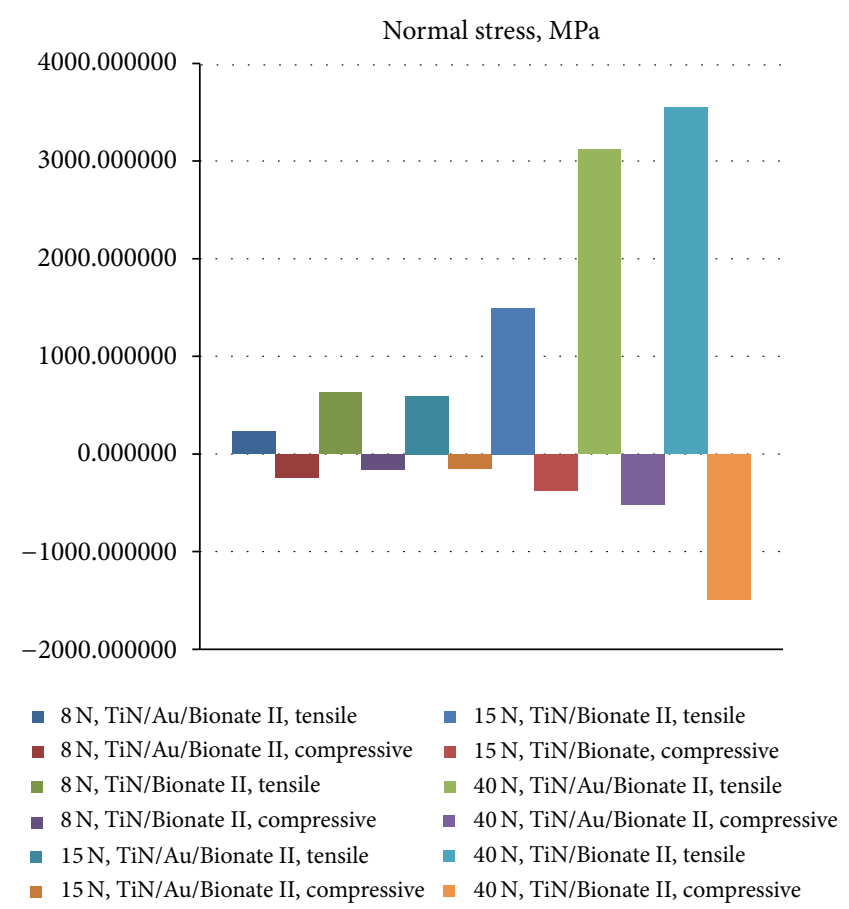

(b)

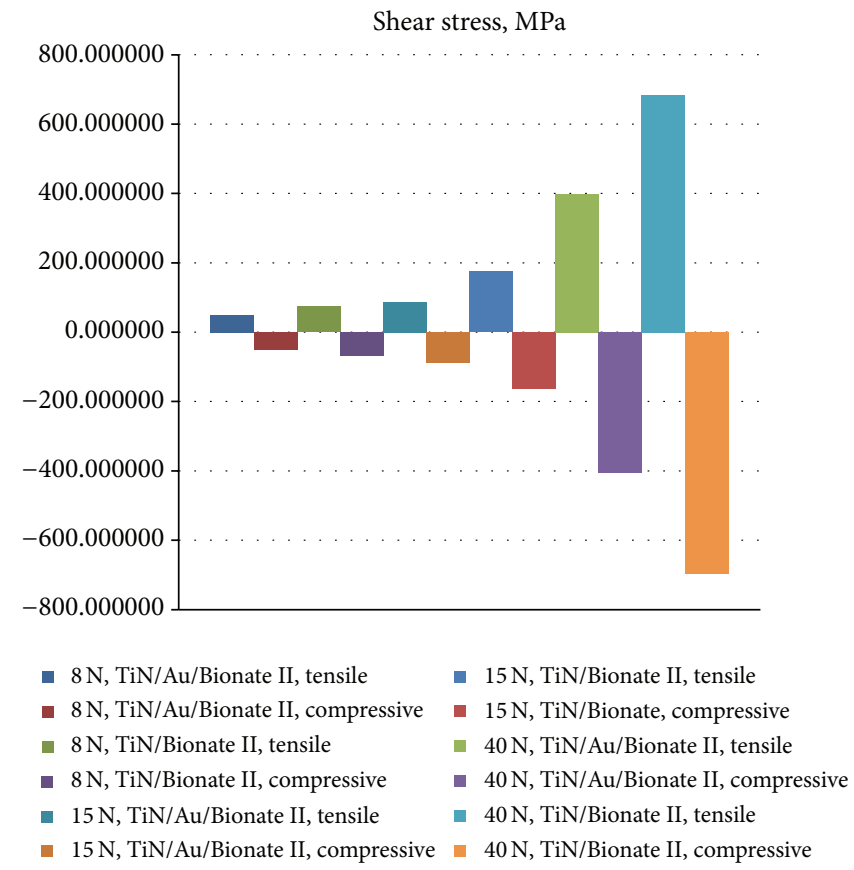

(c)

FIGURE 15: (a) The values of maxima of effective strain $\varepsilon_{i}$ for the FE model of microtension test of samples TiN/Au/PU and TiN/PU stretched at $8 \mathrm{~N}, 15 \mathrm{~N}$, and $40 \mathrm{~N}$. (b) The values of normal stress $\sigma_{x x}$ in MPa for the FE model of microtension test of samples TiN/Au/PU and TiN/PU stretched at $8 \mathrm{~N}, 15 \mathrm{~N}$, and $40 \mathrm{~N}$. (c) The values of shear stress $\sigma_{x y}$ in MPa for the FE model of microtension test of samples TiN/Au/PU and TiN/PU stretched at $8 \mathrm{~N}, 15 \mathrm{~N}$, and $40 \mathrm{~N}$.

percentage of variation between maximum values of tensile normal stress $\sigma_{x x}$ for both samples is observed under the other set of loadings.

The qualitative analysis of distributions of effective strain for both samples shows that the character of distributions is similar under all loadings. The distribution of effective strain in the main part of substrate is homogeneous under all loadings; the exception is the area located close to the boundary between coating and substrate. The distribution of effective strain in the coatings is heterogeneous and it is caused by 
the wave character of coatings and the differences among mechanical properties in the material system. However, the homogenous distribution of effective strain in the coatings is observed in the sample with $\mathrm{Au}$ under the lowest loading. In this case, the maximum of effective strain is located in substrate close to the boundary between coating and substrate in the nodes of wave, and the minimum of effective strain is also located in the same area of sample, but in the amplitude of wave. The biggest values of effective strain are located in the substrate, very close to the boundary between coating and substrate under all loadings in all samples. The maximum of effective strain is located in the amplitude of wave in the substrate and the minimum of effective strain is located in the amplitude of wave on the surface of sample and in the node of wave in the substrate. The biggest influence of $\mathrm{Au}$ coating on the maximum value of effective strain is observed under the lowest and middle loadings. However, the reduction of maximum value of effective strain caused by the Au coating is relatively small under the lowest and middle loadings. The maximum values of effective strain under the biggest loading are almost the same for both samples and they are the biggest from all of the computed values of effective strain (the biggest loading results in the biggest effective strain).

The observations made on the basis of character of distributions and values of stress leads to the conclusion that $\mathrm{Au}$ coating improves the connection between TiN coating and Bionate II substrate, because the computed gradients of stress are smaller. The analysis of character of distribution of effective strain under different loadings also provides a conclusion that $\mathrm{Au}$ buffer layer helps to improve the connection between coating and substrate. It is particularly visible under the lowest and middle loadings when the relative reduction of effective strain caused by the Au layer is clearly observed. The same conclusion is made in the literature, for example, in [19].

\section{Conclusions}

(i) The identification of residual stress in the TiN coating in the material system $\mathrm{TiN} / \mathrm{Au} / \mathrm{PU}$ by a selected analytical model was based on experimental profilometric results, because the XRD methods are not recommended for amorphous materials like polymers and a layer with small domains of the crystalline titanium nitride. The Au nanocoating introduced in the designed material system results in bigger compressive residual stress and bending of the sample; thus, the determination of residual stress was possible by a curvature method.

(ii) The AFM's roughness measurement of coating and the in situ SEM's microtension test provided input data and boundary conditions for the developed micromodels.

(iii) The numerical models of microtension test were adopted to reproduce the experimental microtest and to compare the samples with and without $\mathrm{Au}$ to estimate the influence of $\mathrm{Au}$ buffer coating on the designed material system applied in the wall of heart prosthesis.

(iv) The introduction of $\mathrm{Au}$ interlayer changes a stress state in each layer of the material system TiN/Au/PU. The particularly important is a change of sign of residual stress in the TiN from tensile to compressive. The presence of compressive stresses increases a toughness of connection that significantly decreases the probability of fracture (it is particularly important for the TiN). Due to character of interatomic bonds the compounds are predisposed to be applied under compressive stress load.

\section{Conflict of Interests}

The authors declare that there is no conflict of interests regarding the publication of this paper.

\section{Acknowledgments}

Financial assistance of the National Science Center in Poland, Project no. 2011/01/D/ST8/04087, is acknowledged. The experiments were performed at the WIMiIP AGH University of Science and Technology in Cracow in Poland.

\section{References}

[1] M. Gawlikowski, M. Lewandowski, A. Nowicki et al., "The application of ultrasonic methods to flow measurement and detection of microembolus in heart prostheses," Acta Physica Polonica A, vol. 124, no. 3, pp. 417-420, 2013.

[2] A. Milenin and M. Kopernik, "Multiscale FEM model of artificial heart chamber composed of nanocoatings," Acta of Bioengineering and Biomechanics, vol. 11, no. 2, pp. 13-20, 2009.

[3] M. Kopernik and A. Milenin, "Two-scale finite element model of multilayer blood chamber of POLVAD_EXT," Archives of Civil and Mechanical Engineering, vol. 12, no. 2, pp. 178-185, 2012.

[4] A. Milenin, M. Kopernik, D. Jurkojć et al., "Numerical modelling and verification of Polish ventricular assist device," Acta of Bioengineering and Biomechanics, vol. 14, no. 3, pp. 49-57, 2012.

[5] M. Kopernik, A. Milenin, R. Major, and J. M. Lackner, "Identification of material model of TiN using numerical simulation of nanoindentation test," Materials Science and Technology, vol. 27, no. 3, pp. 604-616, 2011.

[6] A. Milenin and M. Kopernik, "Microscale analysis of strain-stress state for TiN nanocoating of POLVAD and POLVAD_EXT," Acta of Bioengineering and Biomechanics, vol. 13, no. 4, pp. 11-19, 2011.

[7] M. Kopernik and A. Milenin, "Numerical modeling of substrate effect on determination of elastic and plastic properties of TiN nanocoating in nanoindentation test," Archives of Civil and Mechanical Engineering, vol. 14, no. 2, pp. 269-277, 2014.

[8] M. Kopernik, "Failure strainand strain-stress analysis in titanium nitride coatings deposited on Religa Heart Ext ventricular assist device," Archives of Metallurgy and Materials. In press.

[9] M. Kopernik, "Shape optimisation of a ventricular assist device using a VADFEM computer program," Acta of Bioengineering and Biomechanics, vol. 15, no. 3, pp. 81-87, 2013.

[10] A. Milenin and M. Kopernik, "Comparative analysis of ventricular assist devices (POLVAD and POLVAD_EXT) based on 
multiscale FEM model," Acta of Bioengineering and Biomechanics, vol. 13, no. 2, pp. 13-23, 2011.

[11] J. M. Lackner, Industrially-Scaled Hybrid Pulsed Laser Deposition at Room Temperature, Orekop, Kraków, Poland, 2005.

[12] R. Machunze and G. C. A. M. Janssen, "Stress and strain in titanium nitride thin films," Thin Solid Films, vol. 517, no. 20, pp. 5888-5893, 2009.

[13] A. Pramanik and L. C. Zhang, "Residual stresses in silicon-onsapphire thin film systems," International Journal of Solids and Structures, vol. 48, no. 9, pp. 1290-1300, 2011.

[14] R. Eason, Pulsed Laser Deposition of Thin Films Applications-Led Growth of Functional Materials, John Wiley \& Sons, New York, NY, USA, 2007.

[15] J. M. Lackner, W. Waldhauser, P. Hartmann et al., "Selfassembling (nano-)wrinkling topography formation in lowtemperature vacuum deposition on soft polymer surfaces," Thin Solid Films, vol. 520, no. 7, pp. 2833-2840, 2012.

[16] J. Kusinski, S. Kac, A. Kopia et al., "Laser modification of the materials surface layer-a review paper," Bulletin of the Polish Academy of Sciences-Technical Sciences, vol. 60, no. 4, pp. 711728, 2012.

[17] Y. P. Li and G. P. Zhang, "On plasticity and fracture of nanostructured $\mathrm{Cu} / \mathrm{X}(\mathrm{X}=\mathrm{Au}, \mathrm{Cr})$ multilayers: the effects of length scale and interface/boundary," Acta Materialia, vol. 58, no. 11, pp. 3877-3887, 2010.

[18] V. Kotál, V. Švorčík, P. Slepička et al., "Gold coating of poly(ethylene terephthalate) modified by argon plasma," Plasma Processes and Polymers, vol. 4, no. 1, pp. 69-76, 2007.

[19] H. Hirakata, H. Ogiwara, A. Yonezu, and K. Minoshima, "Evaluation of incipient plasticity from interfaces between ultra-thin gold films and compliant substrates," Thin Solid Films, vol. 518, no. 18, pp. 5249-5256, 2010.

[20] P. G. Benardos and G.-C. Vosniakos, "Predicting surface roughness in machining: a review," International Journal of Machine Tools and Manufacture, vol. 43, no. 8, pp. 833-844, 2003.

[21] G. Abadias, "Stress and preferred orientation in nitride-based PVD coatings," Surface and Coatings Technology, vol. 202, no. 11, pp. 2223-2235, 2008.

[22] I. C. Noyan and J. B. Cohen, Residual Stress: Measurement by Diffraction and Interpretation, Springer, New York, NY, USA, 1987.

[23] U. Welzel, J. Ligot, P. Lamparter, A. C. Vermeulen, and E. J. Mittemeijer, "Stress analysis of polycrystalline thin films and surface regions by X-ray diffraction," Journal of Applied Crystallography, vol. 38, no. 1, pp. 1-29, 2005.

[24] S. J. Skrzypek, A. Baczmański, W. Ratuszek, and E. Kusior, “New approach to stress analysis based on grazing-incidence X-ray diffraction," Journal of Applied Crystallography, vol. 34, no. 4, pp. 427-435, 2001.

[25] M. Marciszko, A. Baczmański, K. Wierzbanowski et al., "Application of multireflection grazing incidence method for stress measurements in polished Al_Mg alloy and CrN coating," Applied Surface Science, vol. 226, pp. 256-267, 2013.

[26] M. Marciszko, A. Baczmański, M. Wróbel et al., "Multireflection grazing incidence diffraction used for stress measurements in surface layers," Thin Solid Films, vol. 530, pp. 81-84, 2013.

[27] J. Gunnars and U. Wiklund, "Determination of growth-induced strain and thermo-elastic properties of coatings by curvature measurements," Materials Science and Engineering A, vol. 336, no. 1-2, pp. 7-21, 2002.
[28] A. M. Korsunsky, M. Sebastiani, and E. Bemporad, "Residual stress evaluation at the micrometer scale: analysis of thin coatings by FIB milling and digital image correlation," Surface and Coatings Technology, vol. 205, no. 7, pp. 2393-2403, 2010.

[29] G. G. Stoney, "The tension of metallic films deposited by electrolysis," Proceedings of the Royal Society of London A, vol. 82, no. 553, pp. 172-175, 1909.

[30] S. Timoshenko, "Analysis of bi-metal thermostate," Journal of Optical Society of America and Review Scientific Instruments, vol. 11, p. 233, 1925.

[31] S. Timoshenko, Strength of Materials, D. Van Norstrand Company, New York, NY, USA, 2nd edition, 1940.

[32] E. Suhir, "Stresses in bi-metal thermostats," Journal of Applied Mechanics, vol. 53, no. 3, pp. 657-660, 1986.

[33] E. Suhir, "Interfacial stresses in bimetal thermostats," Journal of Applied Mechanics, vol. 56, no. 3, pp. 595-600, 1989.

[34] W. T. Chen and C. W. Nelson, "Thermal stresses in bonded joints," IBM Journal of Research and Development, vol. 23, no. 2, pp. 179-188, 1979.

[35] Y. Zimin, T. Ueda, and J. Pawłat, "Bonding of silicon and crystal quartz wafers at the minimized residual stresses," Electrical Review, vol. 87, no. 8, pp. 239-242, 2011.

[36] Y.Zimin, T. Ueda, and J. Pawłat, "Energy distribution of residual stresses in bi-layer structure," Electrical Review, vol. 88, no. 6, pp. 111-113, 2012.

[37] L. M. Yin, X. P. Zhang, and C. Lu, "Size and volume effects on the strength of microscale lead-free solder joints," Journal of Electronic Materials, vol. 38, no. 10, pp. 2179-2183, 2009.

[38] Y. L. Su, S. H. Yao, C. S. Wei, C. T. Wu, and W. H. Kao, "Evaluation on the wear, tension and fatigue behavior of various PVD coated materials," Materials Letters, vol. 35, no. 3-4, pp. 255-260, 1998.

[39] Y. L. Su, S. H. Yao, C. S. Wei, and C. T. Wu, "Tension and fatigue behavior of a PVD TiN-coated material," Thin Solid Films, vol. 315, no. 1-2, pp. 153-158, 1998.

[40] P. A. Shade, R. Wheeler, Y. S. Choi, M. D. Uchic, D. M. Dimiduk, and H. L. Fraser, "A combined experimental and simulation study to examine lateral constraint effects on microcompression of single-slip oriented single crystals," Acta Materialia, vol. 57, no. 15, pp. 4580-4587, 2009.

[41] D. Kiener, P. J. Guruprasad, S. M. Keralavarma, G. Dehm, and A. A. Benzerga, "Work hardening in micropillar compression: in situ experiments and modeling," Acta Materialia, vol. 59, no. 10, pp. 3825-3840, 2011.

[42] Y. Gao, Z. L. Liu, X. C. You, and Z. Zhuang, "A hybrid multiscale computational framework of crystal plasticity at submicron scales," Computational Materials Science, vol. 49, no. 3, pp. 672681, 2010.

[43] G. Lasko, Z. Burghard, J. Bill et al., "Simulation of mechanical properties of bio-inspired TiO2/PE nanocomposites," Advanced Engineering Materials, vol. 15, no. 10, pp. 908-920, 2013. 

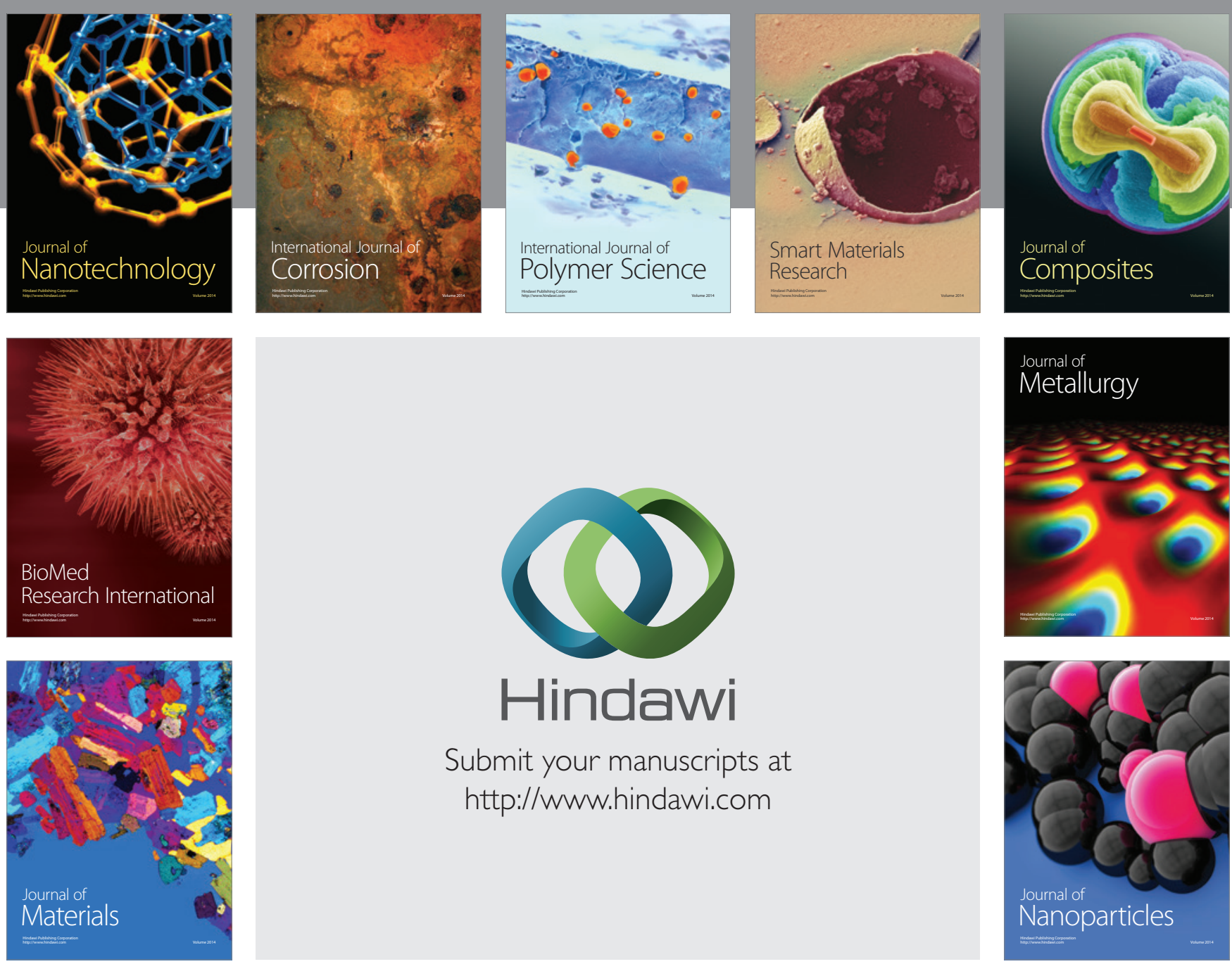

Submit your manuscripts at http://www.hindawi.com
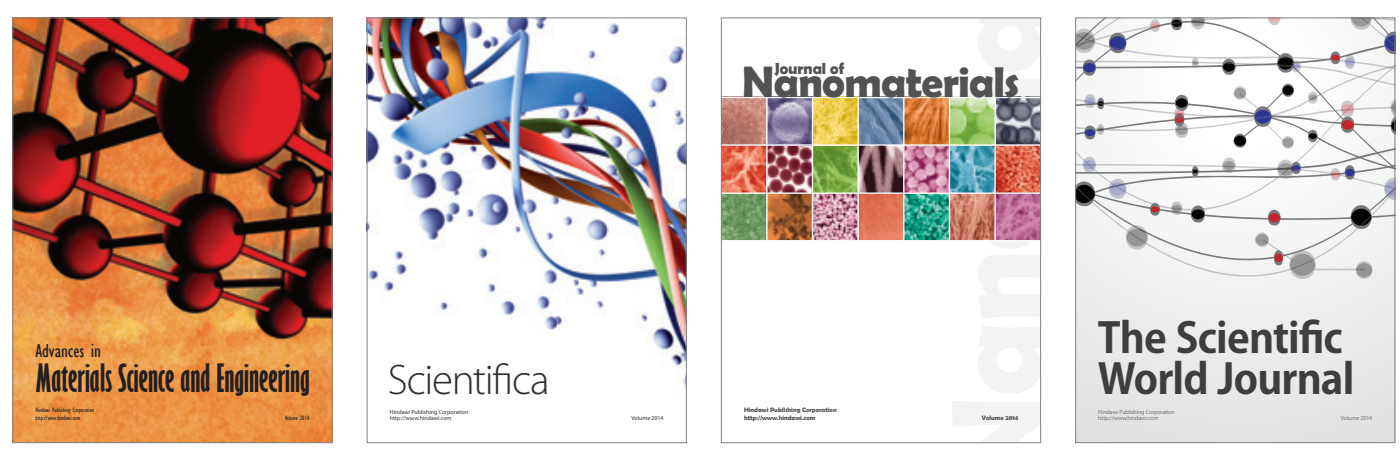

\section{The Scientific World Journal}
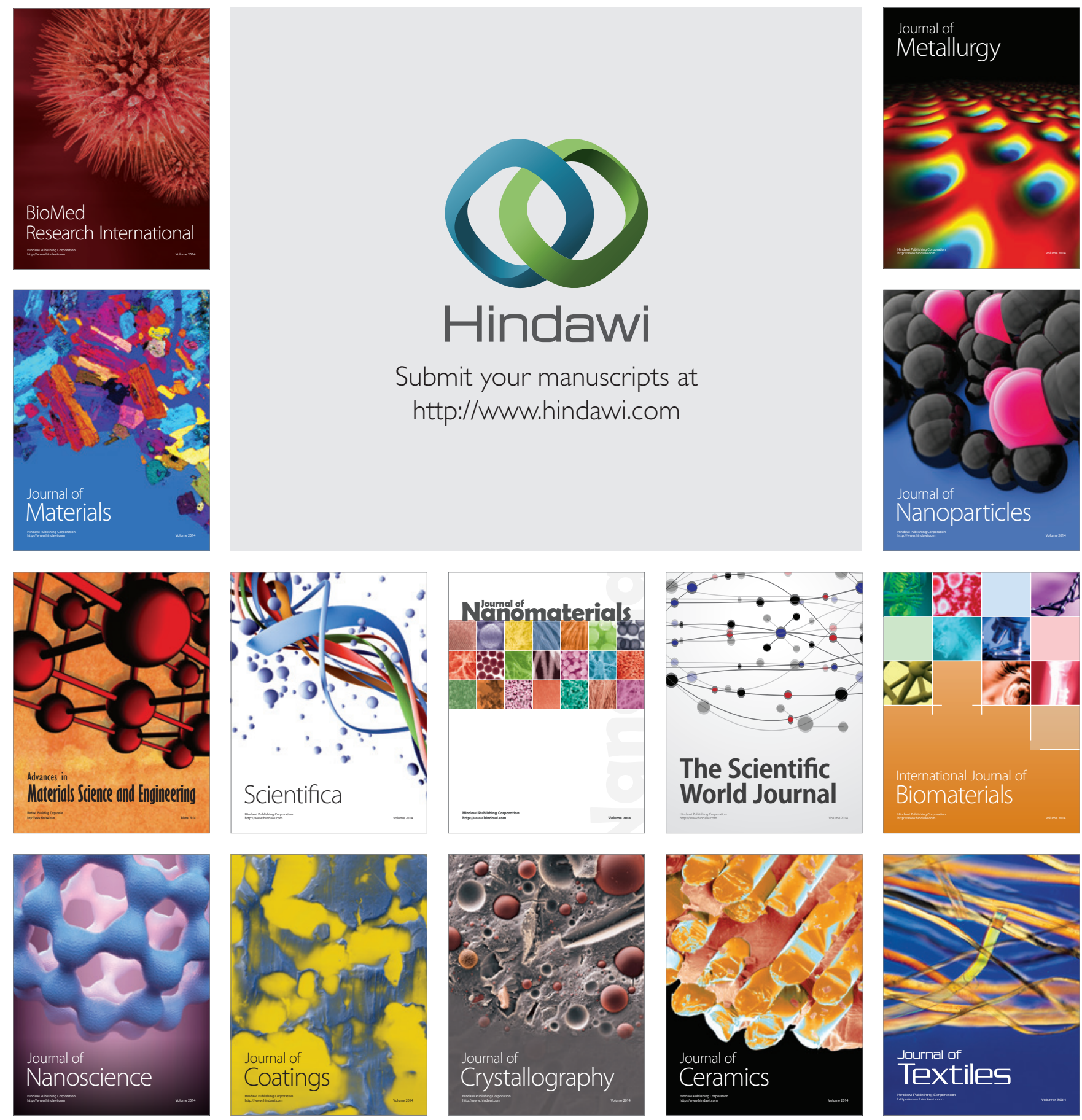